\title{
Do Eosinophilic Polyps Act as a Reliable Predictor of Olfactory Dysfunction and Postoperative Recovery in Chronic Rhinosinusitis?
}

\author{
Donghyuk Im, Young Soo Yang, Hye Rang Choi, Kyujin Han, \\ Seok-Chan Hong, Jae Hoon Cho, and Jin Kook Kim \\ Department of Otorhinolaryngology-Head and Neck Surgery, School of Medicine, Konkuk University, Seoul, Korea
}

\author{
호산구성 비용종을 통해 만성 부비동염 환자의 수술후 후각 기능 회복을 예측할 수 있는가 \\ 임동혁 · 양영수 · 최혜랑 · 한규진 · 홍석찬 · 조재훈 · 김진국 \\ 건국대학교 의학전문대학원 이비인후-두경부외과학교실
}

\author{
Received May 2, 2017 \\ Revised November 2, 2017 \\ Accepted November 8, 2017 \\ Address for correspondence \\ Jin Kook Kim, MD, PhD \\ Department of Otorhinolaryngology- \\ Head and Neck Surgery, \\ School of Medicine, \\ Konkuk University, \\ 120-1 Neungdong-ro, Gwangjin-gu, \\ Seoul 05030, Korea \\ Tel $+82-2-2030-7662$ \\ Fax $+82-2-2030-5299$ \\ E-mail entalk@kuh.ac.kr
}

Background and Objectives The purpose of this study was 1) to assess differences in categories of olfactory dysfunction according to the pathological classification of chronic rhinosinusitis with nasal polyp (CRSwNP) patients; 2) to identify the degree of olfaction recovery after endoscopic sinus surgery (ESS); and 3) to identify the factors that predict the changes in olfactory status.

Subjects and Method The sample of the study consisted of patients with CRSwNP who underwent ESS with biopsy from January 2012 to September 2014. Seventy five patients were classified into eosinophilic CRS (ECRS) and non-ECRS groups. During an approximately fivemonth follow-up, the Korean Version of Sniffin' Sticks test II (KVSS II) was conducted on each patient to examine the difference between the preoperative and postoperative states of olfactory function.

Results The ECRS group showed a statistical significant increase in the postoperative KVSS II scores when compared to the preoperative scores, while the non-ECRS group did not show any statistically significant change. For the anosmia category by KVSS II, the ECRS group showed significantly improved olfactory function test scores for the threshold, discrimination, and identification tests.

Conclusion ECRS and preoperative olfactory function status (anosmia) could be predictable factors of postoperative olfactory function.

Korean J Otorhinolaryngol-Head Neck Surg 2018;61(6):300-7

Key Words Anosmia - Chronic rhinosinusitis · Endoscopic sinus surgery Eosinophilic polyps $\cdot$ Olfaction recovery.

\section{Introduction}

Olfactory dysfunction is one of the well-known symptoms of chronic rhinosinusitis (CRS) and is experienced by $65 \%$

This is an Open Access article distributed under the terms of the Creative Commons Attribution Non-Commercial License (http://creativecommons.org/licenses/by-nc/4.0) which permits unrestricted non-commercial use, distribution, and reproduction in any medium, provided the original work is properly cited. to $80 \%$ of CRS patients. ${ }^{1)}$ Reports of olfactory dysfunction indicate that two-thirds of the cases are caused by diseases related to an upper airway infection, head injury, or nasal cavity and paranasal sinuses. ${ }^{2)}$ Olfactory dysfunction caused by sino-nasal diseases involve conductive and sensorineural causes. Conductive olfactory dysfunction causes obstruction to the access of odor molecules to the olfactory cleft (OC) by the se- 
vere edema of the olfactory membrane or nasal polyp (NP).

Olfactory dysfunction caused by CRS with NP (CRSwNP) has demonstrated satisfactory levels of improvement in olfactory function after receiving treatment. ${ }^{4}$ The CRSwNP can be classified pathologically into eosinophilic CRS (ECRS) and non-ECRS depending on the infiltration degree of the eosinophil. ${ }^{5)}$ There have been several reports of olfactory recovery in CRSwNP cases after endoscopic sinus surgery (ESS); however, the results are not consistent. ${ }^{6-9)}$ In recent literature, the changes and prognostic factors of the olfaction status after ESS have been reported. ${ }^{7-10)}$ A preoperative NP, olfactory function status, findings on the CT scans, and smoking history are some of the predictive factors for the improvement in olfactory function after surgery. ${ }^{11-15)}$

The purpose of this study was first, to evaluate the difference of olfactory dysfunction according to the pathological classification of CRSwNP; and second, to identify the degree of postoperative olfactory recovery depending on the pathological classification; and finally, to identify the predictive factors of olfactory change.

\section{Subjects and Method}

\section{Subject}

This study had a prospective design. The subjects were recruited and categorized into the ECRS and non-ECRS groups until each group had a minimum of 63 patients assigned. A total of 126 patients with a biopsy result of a NP during surgery, diagnosed with CRSwNP and had undergone endoscopic frontoethmoidectomy and polypectomy surgery at the Konkuk University Hospital, Department of Otorhinolaryngology between January 2012 and September 2014, were included in the study. The study was approved by the Institutional Review Board of the Konkuk University Hospital (KUH1110023). Informed consent forms were obtained from all patients prior to surgery and the olfactory function test. After the surgery, the enrolled patients were instructed to take the follow-up olfactory function tests (Korean Version of Sniffin' Sticks Test II, KVSS II) at 1, 3, and 6 months. We excluded patients who did not attend follow-ups consistently according to the follow up schedule or poorly complied with their follow-up medication or management, which led to a considerable attrition during the follow-up phase. Finally, of the 126 patients, only 75 were selected to undergo ESS and received the necessary follow-up for the study. All patients received the same post-operative medical regimen consisting of macrolide antibiotics for an average of 3 weeks after ESS. The mean follow-up period was approximately 5 months and it ranged from one half of a month to 11 months.

\section{Blood examination}

The serum samples were taken from all patients before surgery to identify individual characteristics. We assessed the blood eosinophil percent, total immunoglobulin E ( $\operatorname{IgE}$ ), and eosinophilic cationic protein (ECP).

\section{Evaluation of CT scans on rhinosinusitis}

The Lund-Mackay CT scoring system was used to assess the degree of rhinosinusitis in the maxillary, ethmoid, sphenoid, and frontal sinuses; and the ostiomeatal unit (OMU) and OC. The scores for each of the paranasal sinuses and the OC were assessed as normal (0), partially closed (1), and fully closed (2). The OMU region was evaluated as normal (0) or closed (1). All scores were summed to determine the overall scores for both regions. ${ }^{16)}$ The effect of the ethmoid sinus was evaluated based on the ethmoid/maxillary sinus score ratio (E/M ratio) which is the ratio of the $\mathrm{CT}$ scores for the ethmoid sinus and the maxillary sinus. ${ }^{17)}$

\section{Categorization and assessment of CRSwNP}

NPs were classified as either eosinophilic or non-eosinophilic based upon the biopsy results. The NP tissues were stained with hematoxylin \& eosin, and then 10 regions of the relatively evenly distributed cells were randomly selected using an optical microscopy. We measured the number of eosinophil under high magnification of 400 times. An eosinophilic NP was defined those with a mean that was greater than 100; whereas, non-eosinophilic NP consisted of those with a mean of less than 100 (Fig. 1). ${ }^{18)}$

The assessment of the NPs was graded according to the CT results and intranasal endoscopic findings. A single polyp limited to the middle meatus was scored as 0 . The presence of many polyps that were causing a partial obstruction of the nasal cavity was scored as 1 . Extensive polyps that were causing full obstruction of the nasal cavity or the polyp was in contact with nasal floor was scored as $2 .^{19)}$

\section{Assessment of olfactory function}

Olfactory function was assessed using KVSS II (Burghart Company, Wedel, Germany). Of the 126 patients who had undergone ESS, the KVSS II was administered to 75 people whose follow-up was possible prior and subsequent to the 
surgery. According to the KVSS II scores, the olfactory status of patients were categorized as nomosmia when scores were 28 points or higher, hyposmia when scores ranged from 21 points to 27 points, and anosmia when scores were less than 20 points. $^{20,21)}$

\section{Statistical analysis}

A t-test was used to compare the blood test results, CT findings, and olfactory function test scores across both groups that were differentiated according to the results of the NP biopsy. In addition, paired t-tests were used to compare the change in olfactory functioning in the subjects before and after surgery. A Wilcoxon signed rank test was conducted to compare the recovery of olfactory function between the categorized olfactory groups before and after surgery; and a Kruskal-
Wallis test was conducted to compare CT scores across the categorized olfactory groups. All statistical analyses were conducted with the SPSS version 20.0 software (IBM Corp., Armonk, NY, USA) and a 2-tailed $p$-value of less than 0.05 was considered statistically significant.

\section{Results}

\section{Subjects' characteristics}

Among the 75 patients that were followed after ESS, 34 patients $(45.3 \%)$ and 41 patients $(54.6 \%)$ were assigned to the ECRS and non-ECRS groups, respectively. The average ages of the ECRS and non-ECRS groups were 44.50 \pm 12.46 and $44.17 \pm 18.06$, respectively. The difference was not statistically significant. The preoperative mean blood eosinophilic
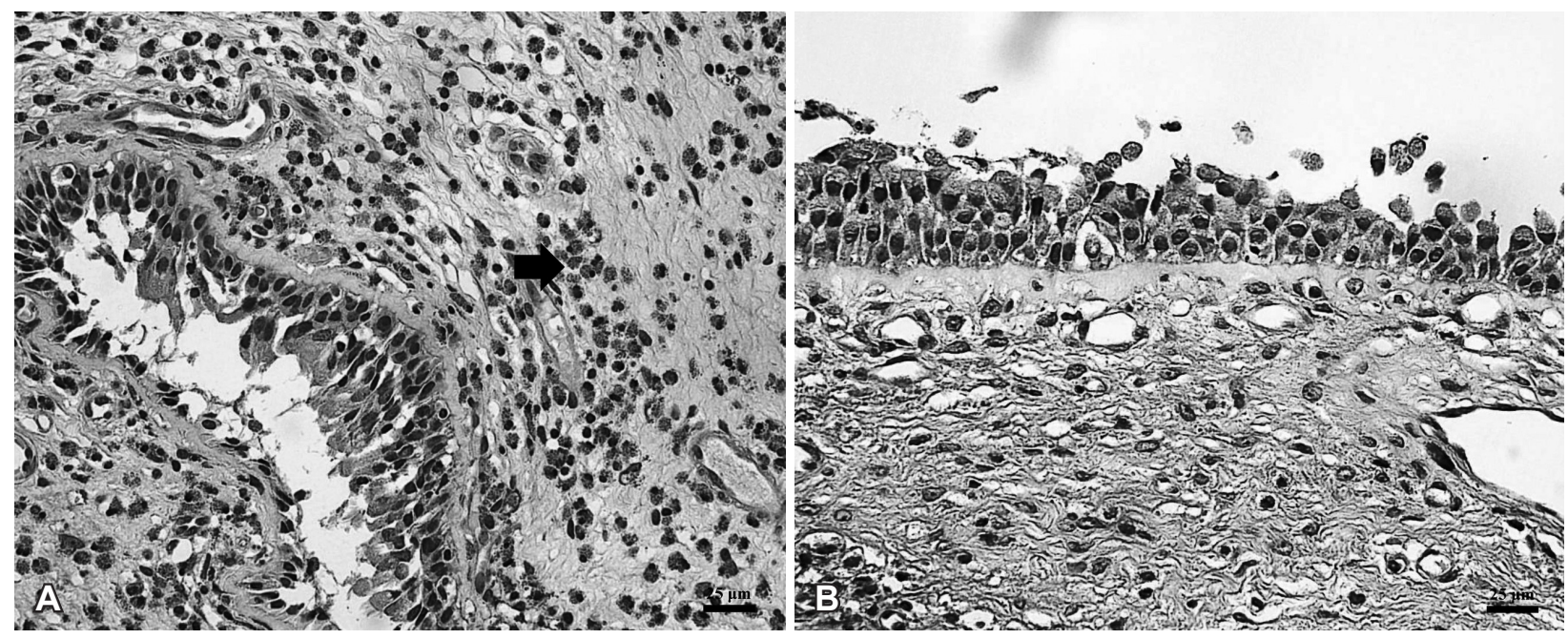

Fig. 1. Typical nasal polyp tissue. Eosinophilic nasal polyp (H\&E, $\times 400)$, eosinophil in nasal polyp tissue (arrow) (A). Non-eosinophilic nasal polyp $(H \& E, \times 400)(B)$.

Table 1. Clinical characteristics of preoperative chronic rhinosinusitis with nasal polyp

\begin{tabular}{lcccc}
\hline & Total $(\mathrm{n}=75)$ & ECRS $(\mathrm{n}=34)$ & non-ECRS $(\mathrm{n}=41)$ & $\mathrm{p}$-value \\
\hline Gender $(\mathrm{m}: \mathrm{f})$ & $51: 24$ & $22: 12$ & $29: 12$ & \\
Age $(\mathrm{yrs})$ & $44.32 \pm 15.67$ & $44.50 \pm 12.46$ & $44.17 \pm 18.06$ & 0.929 \\
Hyposmia & 24 & 11 & 13 & 23 \\
Anosmia & 44 & 21 & $15(36.5)$ & 0.883 \\
Smoking $(\mathrm{n}, \%)$ & $28(37.3)$ & $13(38.2)$ & $12(29.2)$ & 0.578 \\
Allergy $(\mathrm{n}, \%)$ & $24(32.0)$ & $12(35.2)$ & $0(0)$ & 0.115 \\
Asthma ( $\mathrm{n}, \%)$ & $2(2.6)$ & $2(5.8)$ & $3.09 \pm 2.28$ & $0.003^{*}$ \\
Blood eosinophil percentage & $4.34 \pm 3.95$ & $329.63 \pm 524.44$ & $235.31 \pm 829.49$ & 0.576 \\
Total IgE (KU/L) & $279.14 \pm 701.18$ & $41.62 \pm 55.07$ & $21.98 \pm 29.43$ & 0.088 \\
ECP (ug/l) & $30.78 \pm 43.57$ & $2.14 \pm 4.03$ & $2.50 \pm 4.10$ & 0.708 \\
Duration of CRS Sx. (yrs) & $2.34 \pm 4.05$ & $4.98 \pm 4.10$ & $3.75 \pm 2.80$ & 0.129 \\
Follow up period (months) & $4.31 \pm 3.48$ & & \\
\hline
\end{tabular}

*p<0.05, t-test. IgE: immunoglobulin E, ECP: eosinophilic cationic protein, CRS: chronic rhinosinusitis, ECRS: eosinophilic CRS, Sx.: symptom 
Recovery of Olfactory Function after ESS I Im D, et al.

Table 2. Nasal factors from L-M scores and endoscopic status of preoperative chronic rhinosinusitis with nasal polyp

\begin{tabular}{lrrrc}
\hline & Total $(n=75)$ & ECRS $(n=34)$ & non-ECRS $(n=41)$ & $p$-value \\
\hline Total L-M score & $15.75 \pm 8.79$ & $17.35 \pm 7.77$ & $14.41 \pm 9.43$ & 0.151 \\
E/M ratio & $2.30 \pm 1.00$ & $2.45 \pm 1.00$ & $2.18 \pm 0.99$ & 0.262 \\
PE/AE ratio & $0.72 \pm 0.36$ & $0.77 \pm 0.37$ & $0.69 \pm 0.35$ & 0.321 \\
Endoscopic NP grading & $1.87 \pm 0.64$ & $1.79 \pm 0.64$ & $1.93 \pm 0.10$ & 0.378 \\
\hline
\end{tabular}

L-M score: Lund-Mackay score, E/M ratio: ethmoid/maxillary sinus score ratio, PE/AE ratio: posterior ethmoid/anterior ethmoid sinus score ratio, NP: nasal polyp, ECRS: eosinophilic chronic rhinosinusitis

Table 3. Olfactory function test scores in preoperative chronic rhinosinusitis with nasal polyp

\begin{tabular}{lrrrc}
\hline & Total $(n=75)$ & ECRS $(n=34)$ & non-ECRS $(n=41)$ & p-value \\
\hline KVSS II & $18.49 \pm 7.09$ & $17.15 \pm 7.29$ & $19.61 \pm 6.81$ & 0.136 \\
T & $3.71 \pm 3.03$ & $2.76 \pm 2.38$ & $4.49 \pm 3.31$ & $0.013^{*}$ \\
D & $6.93 \pm 2.93$ & $6.62 \pm 3.17$ & $7.20 \pm 2.74$ & 0.400 \\
I & $8.07 \pm 3.53$ & $8.24 \pm 3.87$ & $7.93 \pm 3.27$ & 0.710 \\
\hline
\end{tabular}

*p<0.05. KVSS II: Korean Version of Sniffin' Sticks test II, T: Threshold test, D: Discrimination test, I: Identification test, ECRS: eosinophilic chronic rhinosinusitis

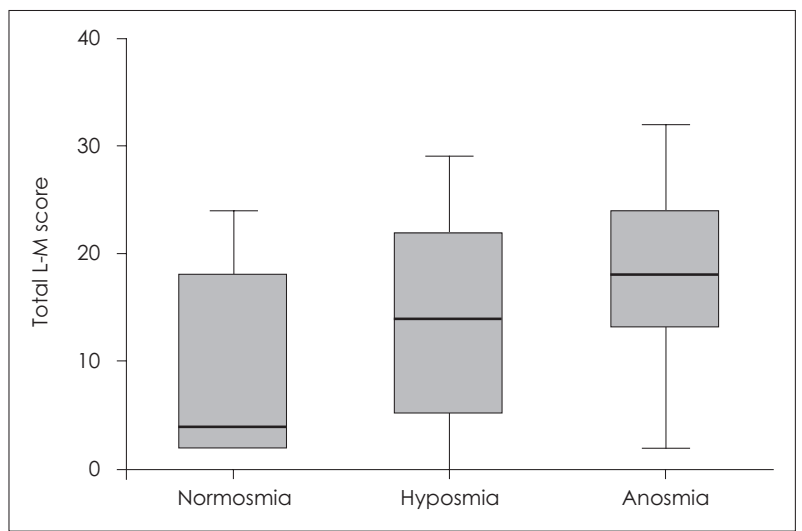

Fig. 2. CT scores of diagnostic groups by Korean Version of Sniffin' Sticks test II in chronic rhinosinusitis with nasal polyp. L-M score: Lund-Mackay score.

percentage was significantly higher in the ECRS group $(p=0.00)$ (Table 1). The serum total IgE and ECP levels tended to be higher in the ECRS group than the non-ECRS group but the differences were not statistically significant ( $p=0.57$, $p=0.08$ ). The OMU scores based upon the Lund-Mackay CT method were significantly different with scores of $3.35 \pm 1.17$ in the ECRS group and $2.68 \pm 1.36$ in the non-ECRS group $(p=0.03)$. On the other hand, the OC scores were not significantly different between the two groups $(2.14 \pm 1.63$ and $2.09 \pm 1.70$ in the ECRS and non-ECRS groups, respectively, $p=0.80$ ). In addition, the endoscopic NP grading was $1.79 \pm$ 0.64 and $1.93 \pm 0.10$ in the ECRS and non-ECRS groups, respectively. The difference between the groups was not statistically significant ( $p=0.37$ ) (Table 2 ).

\section{Evaluation of preoperative olfactory function}

The preoperative olfactory function in both groups as mea- sured by the KVSS II was not significantly different (17.2 \pm 7.3 vs. 19.6 \pm 6.8 in the ECRS and non-ECRS groups, respectively, $p=0.14$ ). The Threshold (T) test score from the KVSS II was $2.76 \pm 2.38$ in the ECRS group, which was significantly lower than the score of $4.49 \pm 3.31$ in the non-ECRS group $(p=0.01)$. However, the Discrimination (D) test scores $(6.62 \pm$ 3.17 vs. $7.20 \pm 2.74$ in the ECRS and non-ECRS groups, respectively) and Identification (I) test scores (8.24 \pm 3.87 vs. $7.93 \pm 3.27$ in the ECRS and non-ECRS groups, respectively) were not affected by the eosinophil infiltration within the tissues ( $p=0.40, p=0.71)$ (Table 3 ). When comparing the olfaction status as measured by the total Lund-Mackay CT and KVSS II scores prior to surgery, a significantly higher total LundMackay CT score was observed in cases of severe olfactory disorder ( $p=0.04)$ (Fig. 2).

\section{Evaluation of postoperative olfactory function}

The olfactory function test scores for CRSwNP patients were $18.49 \pm 7.09$ and $19.79 \pm 5.88$ prior and subsequent to surgery, respectively, but the difference was not statistically significant $(p=0.09)$. The T.D.I score was also not statistically significant different before and after surgery. However, in the ECRS group, the T.D.I score of the ECRS group's KVSS II significantly improved from $17.15 \pm 7.29$ before surgery to $20.15 \pm 6.10$ after the surgery $(p=0.03)$. Each patient's change in T.D.I score in the ECRS group did not result in a statistically significant improvement after the surgery. In the nonECRS group, the T.D.I score did not significantly improve after surgery with mean scores of $19.61 \pm 6.81$ and $19.49 \pm$ 5.74 before and after surgery, respectively $(p=0.08)$. Further analyses at the individual level demonstrated that the T.D.I 
Table 4. Changes of postoperative olfactory function test scores

\begin{tabular}{lccc}
\hline & $\begin{array}{c}\text { Preoperative } \\
\text { OFT scores } \\
(\mathrm{n}=75)\end{array}$ & $\begin{array}{c}\text { Postoperative } \\
\text { OFT scores } \\
(\mathrm{n}=75)\end{array}$ & p-value \\
\hline CRSWNP & & & \\
KVSS II & $18.49 \pm 7.09$ & $19.79 \pm 5.88$ & 0.098 \\
T & $3.71 \pm 3.03$ & $3.56 \pm 2.62$ & 0.699 \\
D & $6.93 \pm 2.93$ & $7.57 \pm 3.10$ & 0.130 \\
I & $8.07 \pm 3.53$ & $8.67 \pm 3.14$ & 0.122 \\
ECRS group & & & \\
KVSS II & $17.15 \pm 7.29$ & $20.15 \pm 6.10$ & $0.030^{*}$ \\
T & $2.76 \pm 2.38$ & $3.24 \pm 2.58$ & 0.410 \\
D & $6.62 \pm 3.17$ & $7.88 \pm 3.41$ & 0.069 \\
I & $8.24 \pm 3.87$ & $9.12 \pm 3.08$ & 0.183 \\
non-ECRS group & & & \\
KVSS II & $19.61 \pm 6.81$ & $19.49 \pm 5.74$ & 0.886 \\
T & $4.49 \pm 3.31$ & $3.83 \pm 2.65$ & 0.196 \\
D & $7.20 \pm 2.74$ & $7.32 \pm 2.84$ & 0.814 \\
I & $7.93 \pm 3.27$ & $8.29 \pm 3.18$ & 0.426 \\
\hline
\end{tabular}

$* p<0.05$, paired t-test. CRSWNP: chronic rhinosinusitis with nasal polyp, KVSS II: Korean Version of Sniffin' Sticks test II, T: Threshold test, D: Discrimination test, I: Identification test, OFT: olfactory function test score was also not significantly different between before and after surgery (Table 4).

Amongst the categorized olfactory groups, the anosmia group showed significant improvement in the olfactory function test after surgery in both the ECRS group and nonECRS group ( $p=0.01,0.03$, respectively) (Fig. 3). In the anosmia patient group, the T.D.I scores significantly improved in both groups. The T.D.I scores in the ECRS group also demonstrated significant improvement at the individual level $(p<0.05)$; whereas, the non-ECRS group did not (Fig. 4).

Therefore, ECRS group shows faster recovery of olfaction than non-ECRS group.

\section{Discussion}

Olfactory dysfunction is included as one of the diagnostic criteria of CRS. In addition, the reduction of smell appears at a relatively early stage in ECRS, as compared to nonECRS $^{14)}$ groups. When a NP occurred, it did so commonly in the middle meatus, middle turbinate, and OC in the ECRS
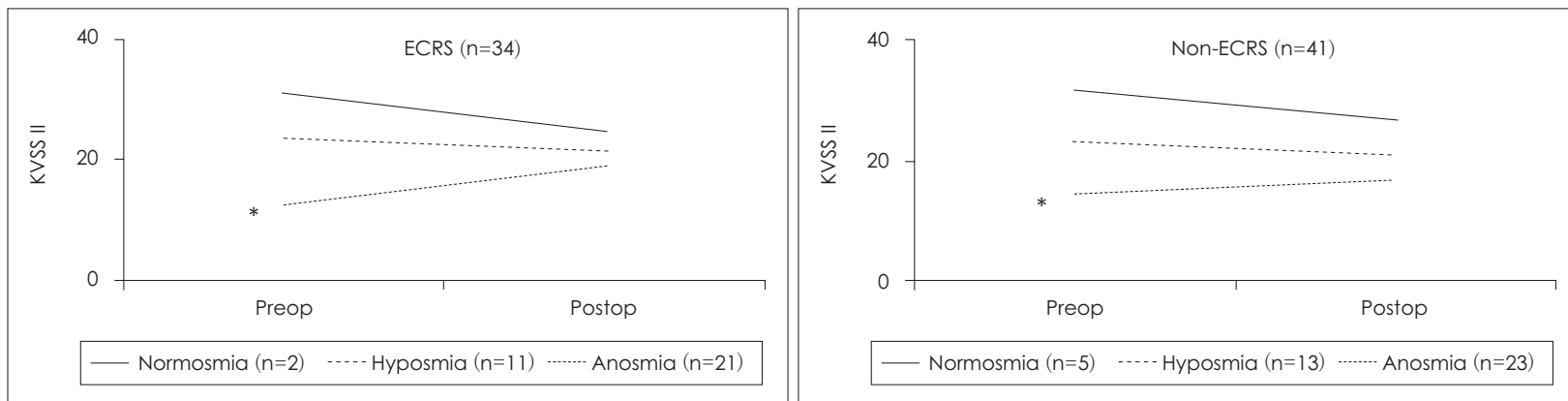

Fig. 3. Changes of postoperative olfactory function test scores (KVSS II). (*) denotes statistical significance. ECRS: eosinophilic chronic rhinosinusitis, KVSS II: Korean Version of Sniffin' Sticks test II, Preop: preoperative, Postop: postoperative.
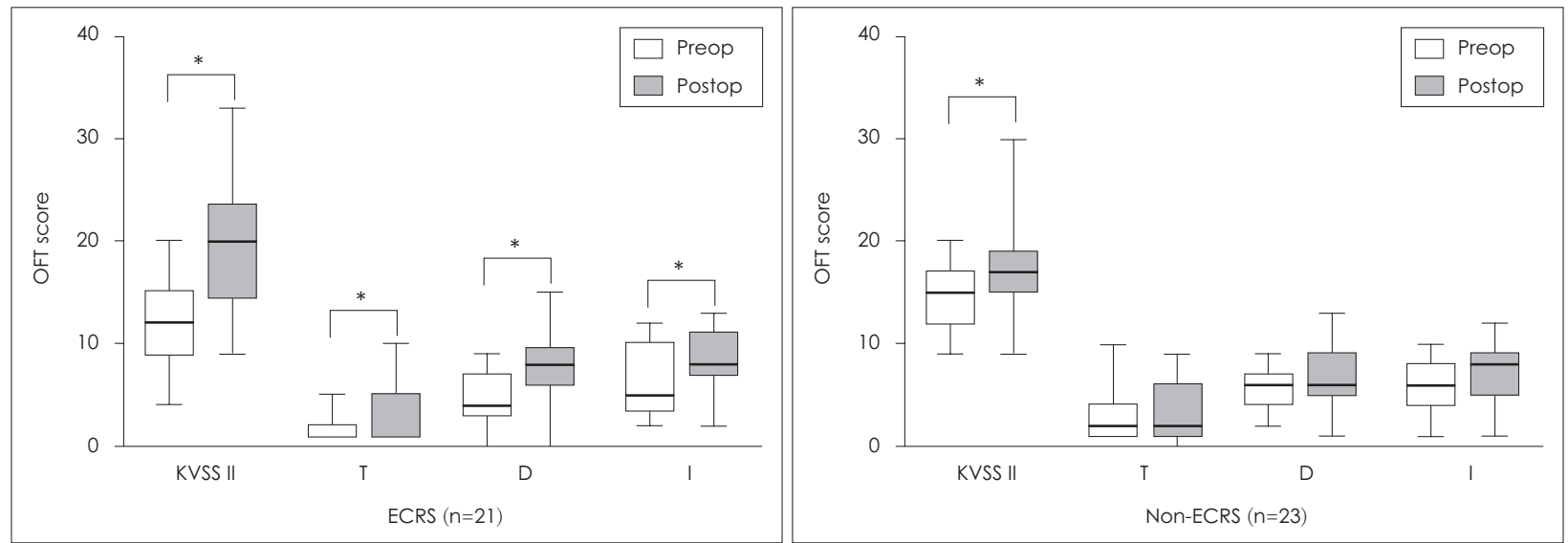

Fig. 4. Changes of postoperative olfactory function test scores in anosmia group for ECRS and non-ECRS patients. $(*)$ denotes statistical significance. OFT: olfactory function test, ECRS: eosinophilic chronic rhinosinusitis, KVSS II: Korean Version of Sniffin' Sticks test II, T: Threshold test, D: Discrimination test, I: Identification test, Preop: preoperative, Postop: postoperative. 
group. Whereas, in the non-ECRS group, it was known to have commonly occurred in the middle meatus only. So ECRS has been known to have a greater impact on olfaction. ${ }^{14)}$ Ishitoya, et al. ${ }^{14)}$ reported that the maxillary sinus and OMU were the primary lesions in the non-ECRS group and the ethmoid sinus and OC regions were the main early lesions found in the ECRS group based upon the Lund-Mackay CT scores. This study exhibited similar results as those in previous studies; however, there were generally no statistically significant differences between the groups. As a result, we suggested that the disease severity of the olfactory outcomes according to CT scores are not significantly different between the ECRS and non-ECRS groups.

In a study conducted with Korean subjects in 2010, eosinophilic allergic polyps, defined as those with a tissue eosinophil proportion more than $11 \%$, reportedly had an incidence rate of $62.7 \%{ }^{22)}$ Olfactory dysfunction was more serious in the ECRS group before surgery than that found in the nonECRS group. The results of this study indicated that the preoperative olfactory function was lower in the ECRS group than in the non-ECRS group, and the threshold scores, especially, of the ECRS group were significantly lower than the non-ECRS group. The involvement of NPs in either the ethmoid sinus or OC was more frequent in the ECRS group which produced a greater effect on conductive olfactory dysfunction. Furthermore, the E/M ratio of the ECRS group as measured by the CT findings was higher which is consistent with the high scores reported for the ethmoid sinus and OC. Ishitoya, et al. ${ }^{14)}$ reported that hyposmia was an early symptom in the ECRS group, unlike the non-ECRS group. Likewise, the CT findings revealed ethmoid predominance in the ECRS group only. In other study in China, Meng, et al. ${ }^{23)}$ reported that E/M ratio of ECRS group was significantly higher than that of non-ECRS group. However, in this study the ECRS group showed $2.45 \pm 1.00$ and non-ECRS group showed $2.18 \pm 0.99$, so that it was not statistically significant but the ECRS group had a tendency of higher figures than the non-ECRS group.

The olfactory recovery in CRS after surgery reportedly showed a range of improvement in olfactory function that varied from $23 \%$ to $85 \%{ }^{6-9)}$ Moreover, olfactory function improved at the short-term follow up, but there was no distinct difference in olfactory function at the long-term follow up. ${ }^{24)}$ Also, ESS had no effect on the olfactory improvement in CRS. ${ }^{8)}$ A study on CRSwNP, with a follow-up of 3-4 months after surgery showed that olfactory function was markedly improved as compared to CRS without NP. However, subsequently, there were hardly any changes in olfactory function. ${ }^{19)}$ In this study, olfactory function did not improve significantly after the surgery of overall CRSwNP. However, in the ECRS group, the post-surgical olfactory function improved significantly than that found in the non-ECRS group. According to Pade and Hummel, ${ }^{7)}$ the improvement of olfactory function after the surgery was observed in $23 \%$ of the cases. While $68 \%$ of the cases experienced no change and $9 \%$ took a serious turn. Furthermore, the olfaction of CRS with NP and eosinophilia showed distinct improvement. In this study, the olfaction improvement was $53 \%$ but was worse in $36 \%$ of the cases. No change occurred in $11 \%$ of the cases. Yet, the improvement experienced in the ECRS group was remarkable. Oka, et al. ${ }^{4)}$ reported that until 6 months after ESS, the olfactory function improved in both groups, and those in the ECRS group especially showed more significant improvement than those in the non-ECRS group. However, it was reported that at long-term follow up, the non-ECRS group showed more improvement in olfactory function.

When we compared the olfactory function test scores of the categorized olfactory groups before and after surgery, the olfactory function of anosmia group showed a remarkable improvement than did those in the normosmia and hyposmia groups. However, despite the improved olfactory function of anosmia group, it did not recover to a normal olfaction range. Litvack, et al. ${ }^{10)}$ also reported that the anosmia group had remarkable improvement in olfactory function compared to the hyposmia group after the surgery and for a year of follow-up. After the removal of the NP, the nasal patency of the anosmia group improved rapidly, regardless of the presence of ECRS. CRS is a disease that includes both conductive and sensorineural type olfactory dysfunction, and in the preoperative anosmia group, the conductive type of olfactory dysfunction has a higher possibility of recovery after operation. Poor olfactory function before the surgery generally results in more remarkable early improvement in olfactory function. However, this result could be different if traced over a longer term follow up and the mucosal condition at the time of observation was noted. In the anosmia group, the T.D.I scores in the ECRS group significantly improved in each item, while this was not the case with the T.D.I scores in the non-ECRS group. Thus, in the case of olfactory dysfunction due to NP, ESS has an impact on nasal patency.

In this study, considering the influence of ESS on olfactory function, the pathological degree of eosinophil infiltration 
affected the patients' preoperative olfactory status and postoperative olfactory recovery. Furthermore, olfaction improved markedly after the surgery in the anosmia group. Litvack, et al. ${ }^{10)}$ reported that a NP was a predictable factor for olfaction improvement after surgery, while Pade and Hummel ${ }^{7)}$ asserted that a NP and eosinophil infiltration were the predictable factors of olfactory recovery after the surgery. In contrast, Soler, et al. ${ }^{25)}$ reported that the infiltrative degree of eosinophil in the tissues was related to the olfactory dysfunction through its involvement with hypertrophy of the basement membrane of olfactory epithelium; but, there were no predictable factors related to olfaction improvement after the surgery.

In this study, 1) the olfactory function of the ECRS group was lower than that of the non-ECRS group in preoperative state; and, 2) the ECRS group showed more remarkable improvement in olfactory function after the surgery than that experienced by the non-ECRS group. The olfactory function in preoperative state in the anosmia group was especially distinct. Thus, as a result, the infiltrative degree of eosinophil in the tissues and preoperative olfactory function status (anosmia) could be predictable factors of preoperative olfactory function. Furthermore, it would be worth to compare the degree of improvement of olfactory function between ECRS and non-ECRS after ESS depending on OC score, so that we are also planning to study in the future.

There were some limitations to this study. Patients who underwent olfactory testing after surgery had a high attrition rate. There was also a considerable amount of attrition due to the exclusion criteria.

Out of the 126 patients, only 75 subjects consented to carry on the olfactory testing due to the time-consuming nature of the olfactory function test. Moreover, the patients' subjective opinions that determining change in olfaction was of little necessity was not surprising since they had already experienced improvement in olfaction after the surgery. Additionally, we conducted the re-evaluation of the olfactory function after ESS only once, and since it usually takes 6 months for the olfactory epithelium to recover, the approximate 5-month follow-up period was relatively short. Hence, subsequent longterm follow-ups and serial observations are required.

\section{Acknowledgments}

This research was supported by Basic Science Research Program through the National Research Foundation of Korea (NRF) funded by the Ministry of Education (NRF-2016R1D1A1B01012705).

\section{REFERENCES}

1) Rosenfeld RM, Andes D, Bhattacharyya N, Cheung D, Eisenberg
S, Ganiats TG, et al. Clinical practice guideline: adult sinusitis. Otolaryngol Head Neck Surg 2007;137(3 Suppl):S1-31.

2) Gaines A. Chapter 13: olfactory disorders. Am J Rhinol Allergy 2013; 27 Suppl 1:S45-7.

3) Kern RC. Chronic sinusitis and anosmia: pathologic changes in the olfactory mucosa. Laryngoscope 2000;110(7):1071-7.

4) Oka H, Tsuzuki K, Takebayashi H, Kojima Y, Daimon T, Sakagami M. Olfactory changes after endoscopic sinus surgery in patients with chronic rhinosinusitis. Auris Nasus Larynx 2013;40(5):452-7.

5) Nakayama T, Yoshikawa M, Asaka D, Okushi T, Matsuwaki Y, Otori N, et al. Mucosal eosinophilia and recurrence of nasal polyps - new classification of chronic rhinosinusitis. Rhinology 2011;49(4): 392-6.

6) Danielides V, Katotomichelakis M, Balatsouras D, Riga M, Tripsianis G, Simopoulou M, et al. Improvement of olfaction after endoscopic sinus surgery in smokers and nonsmokers. Ann Otol Rhinol Laryngol 2009;118(1):13-20.

7) Pade J, Hummel T. Olfactory function following nasal surgery. Laryngoscope 2008;118(7):1260-4.

8) Jiang RS, Lu FJ, Liang KL, Shiao JY, Su MC, Hsin CH, et al. Olfactory function in patients with chronic rhinosinusitis before and after functional endoscopic sinus surgery. Am J Rhinol 2008;22(4):445-8.

9) Soler ZM, Sauer DA, Mace JC, Smith TL. Ethmoid histopathology does not predict olfactory outcomes after endoscopic sinus surgery. Am J Rhinol Allergy 2010;24(4):281-5.

10) Litvack JR, Mace JC, Smith TL. Olfactory function and disease severity in chronic rhinosinusitis. Am J Rhinol Allergy 2009;23(2): $139-44$.

11) Kim DW, Kim JY, Kim SW, Jeon SY. Postoperative olfactory results in chronic rhinosinusitis with nasal polyposis according to wound healing status. Clin Exp Otorhinolaryngol 2013;6(3):146-51.

12) Sugiyama K, Matsuda T, Kondo H, Mitsuya S, Hashiba M, Murakami $\mathrm{S}$, et al. Postoperative olfaction in chronic sinusitis: smokers versus nonsmokers. Ann Otol Rhinol Laryngol 2002;111(11):1054-8.

13) Konstantinidis I, Triaridis S, Printza A, Vital V, Ferekidis E, Constantinidis J. Olfactory dysfunction in nasal polyposis: correlation with computed tomography findings. ORL J Otorhinolaryngol Relat Spec 2007;69(4):226-32.

14) Ishitoya J, Sakuma Y, Tsukuda M. Eosinophilic chronic rhinosinusitis in Japan. Allergol Int 2010;59(3):239-45.

15) Rudmik L, Smith TL. Olfactory improvement after endoscopic sinus surgery. Curr Opin Otolaryngol Head Neck Surg 2012;20(1):29-32.

16) Lund VJ, Mackay IS. Staging in rhinosinusitus. Rhinology 1993; 31(4):183-4.

17) Sakuma Y, Ishitoya J, Komatsu M, Shiono O, Hirama M, Yamashita $\mathrm{Y}$, et al. New clinical diagnostic criteria for eosinophilic chronic rhinosinusitis. Auris Nasus Larynx 2011;38(5):583-8.

18) Ikeda K, Shiozawa A, Ono N, Kusunoki T, Hirotsu M, Homma H, et al. Subclassification of chronic rhinosinusitis with nasal polyp based on eosinophil and neutrophil. Laryngoscope 2013;123(11): E1-9.

19) Lildholdt T, Rundcrantz H, Bende M, Larsen K. Glucocorticoid treatment for nasal polyps. The use of topical budesonide powder, intramuscular betamethasone, and surgical treatment. Arch Otolaryngol Head Neck Surg 1997;123(6):595-600.

20) Hong SM, Park IH, Kim KM, Shin JM, Lee HM. Relationship between the Korean Version of the Sniffin' Stick Test and the T\&T olfactometer in the Korean population. Clin Exp Otorhinolaryngol 2011;4(4):184-7.

21) Kim JM, Jeong MS, Shin DH, Seol JH, Hong SC, Cho JH, et al. Olfactory identification test using familiar distracters for koreans. Clin Exp Otorhinolaryngol 2014;7(1):19-23.

22) Jeong WJ, Lee CH, Cho SH, Rhee CS. Eosinophilic allergic polyp: a clinically oriented concept of nasal polyp. Otolaryngol Head Neck 
Surg 2011;144(2):241-6.

23) Meng YF, Lou HF, Wang CS, Zhang L. [The value of sinonasal CT scan in diagnosing of eosinophilic chronic rhinosinusitis with nasal polyps]. Zhonghua Er Bi Yan Hou Tou Jing Wai Ke Za Zhi 2017;52(2): 93-8.

24) Schriever VA, Gupta N, Pade J, Szewczynska M, Hummel T.
Olfactory function following nasal surgery: a 1-year follow-up. Eur Arch Otorhinolaryngol 2013;270(1):107-11.

25) Soler ZM, Sauer DA, Mace J, Smith TL. Relationship between clinical measures and histopathologic findings in chronic rhinosinusitis. Otolaryngol Head Neck Surg 2009;141(4):454-61. 